\title{
Hydrological and hydraulic modelling of the Nyl River floodplain Part 1. Background and hydrological modelling
}

\author{
CFB Havenga ${ }^{1}$, WV Pitman ${ }^{2}$ and AK Bailey ${ }^{2 *}$ \\ ${ }^{1}$ Department of Water Affairs and Forestry, South Africa \\ ${ }^{2}$ Stewart Scott International, South Africa
}

\begin{abstract}
The Nyl River floodplain is a seasonal wetland of great conservation importance in Limpopo Province, South Africa. Water resource developments in the upstream catchments are changing the quantity and timing of water delivery to the floodplain, and this is expected to have an ecological impact. Hydrological and hydraulic models have been developed to help assess this impact. This paper describes the calibration and application of hydrological models of the contributing catchments. The hydraulic modelling and scenario applications to predict changes to vegetation habitat associated with upstream developments are presented in two companion papers. Hydrological simulations were performed using two models, one using daily time steps and the other using monthly time steps. The models were calibrated using historical data on 10 gauged catchments. Their performance was similar in producing average monthly and annual flows, although the higher resolution daily model agreed more closely with the historical data. Simulated estimates of mean annual runoff values for individual catchments compared well with results from previous studies. The daily model also predicted acceptable measures of probability distributions of maximum annual daily flows and daily flows exceeding a specified threshold.
\end{abstract}

Keywords: Nylsvley, Nylsvlei, Nyl River floodplain, WRSM2000, wetland, hydrological modelling

\section{Background}

The Nyl River floodplain is a seasonal wetland in the semi-arid Limpopo Province in the north of South Africa (Fig. 1). With an area of about 24250 ha and a length of about $70 \mathrm{~km}$, it is the largest example of a floodplain wetland in South Africa (Rogers and Higgins, 1993). This internationally renowned conservation area incorporates the Nylsvley Nature Reserve, a designated RAMSAR Wetland of International Importance, and is home to more than 420 bird species, including 102 water birds, of which 58 breed on the floodplain. It supports $61 \%$ of the breeding population of inland water birds south of the Zambezi and Cunene Rivers, and $92 \%$ of Southern African water bird species have been recorded here at some time. Other inhabitants of the river and the floodplain are 70 mammal species, 58 reptile species, 16 fish species and about 10000 insect species (Tarboton, 1987).

The floodplain owes its existence to the geological characteristics of the region, having formed in a basin created by the Zebediela Fault at its downstream end (Tooth et al., 2001). The basin lies at an altitude of about $1100 \mathrm{~m}$ above sea level, between the Waterberg Mountains to the north-west and the Springbok Flats, a large featureless expanse, to the south-east. In its upper reach the floodplain is confined to the local synclinal basin and is relatively narrow $(<1.8 \mathrm{~km}$ wide). The river channel gradually decreases in size through the Nylsvley Nature Reserve (Fig. 2), and eventually disappears to form an extensive, flat floodplain at the lower end of the study area. Beyond the Zebediela Fault, the channel reforms as the Mogalakwena River which joins the Limpopo River $250 \mathrm{~km}$ further north and ultimately reaches the Indian Ocean.

The floodplain and contributing catchments lie in the sum-

\footnotetext{
* To whom all correspondence should be addressed.

푱 +27 11 798-6229; fax: +27 11 798-6012;

e-mail: allanb@ssi.co.za

Received 16 May 2006; accepted in revised form 12 October 2006.
}

mer rainfall region of South Africa. The mean annual rainfall is about $620 \mathrm{~mm}$, usually occurring as thundershowers with a small areal extent, but is highly variable and can range from 250 $\mathrm{mm}$ to $1100 \mathrm{~mm}$ within a 15- to 21-year cycle (Tooth et al., 2001). The streams supplying the floodplain with water rise in the Waterberg Mountains on its north-western side, with negligible contribution from the Springbok Flats to the south- east. The main streams are the Groot Nyl, Klein Nyl, Olifantspruit, Middelfonteinspruit, Bad se Loop, Tobiasspruit, Andriesspruit and Dorpspruit (Fig. 1). On average, flows from these streams cause inundation of at least parts of the floodplain in three out of every five years during the summer season between October and April. Only occasionally do the floodwaters persist throughout a year to the following wet season.

Developments in the study area have mainly been increases in the areas irrigated. Over the last 70 years the area of irrigation has increased from about $1.5 \mathrm{~km}^{2}$ to about $9 \mathrm{~km}^{2}$ which translates into an increased water demand of about $4 \times 10^{6} \mathrm{~m}^{3}$. The catchment with flow-gauge A6H010 on the Bad se Loop tributary shows the largest amount of irrigation and therefore flow entering the Nyl River from this tributary would have decreased over the years accordingly. Also of importance in this regard are the catchments upstream of flow-gauges A6H006 and A6H011 (Klein Nyl and Groot Nyl Rivers respectively).

Increasing water resource development for urban and agricultural use is taking place in the catchments of the contributing streams, and this affects the delivery of water to the floodplain. Because water is one of the fundamental drivers of the ecological functioning of the floodplain, such development must have ecological consequences and these need to be recognised and quantitatively described in development planning. Development directly influences the catchment hydrology through land-use changes and extraction of water from rivers, and hence the quantity and timing of water delivered to the floodplain. The water delivered to the floodplain produces hydraulic conditions such 
as flow depth, velocity and areal extent of inundation that define aquatic habitat characteristics to which biota respond, either directly or indirectly. Although the nature and magnitude of development-related impacts are difficult to predict, they have become an important issue in planning and management of the water resources.

In 1986, the Nylstroom (now Modimolle) Municipality initiated an investigation to identify ways of augmenting water supplies to meet anticipated increasing water requirements in the town. A storage dam on the Olifantspruit was identified by their consultants (Theron et al., 1991) as the most attractive option, and a subsidy was sought from the Department of Water Affairs and Forestry (DWAF) for its construction. The proposal was opposed by the former Nature Conservation Directorate of the Transvaal Provincial Administration, who considered the ecological impact on the floodplain to be undesirable. A conference held in Nylstroom in 1991 to address the issue concluded that although the dam was the best technical option to augment the town's water supplies, the hydrological and hydraulic behaviour of the floodplain was insufficiently understood for its impacts to be assessed reliably. The behaviour of the floodplain, particularly within the Nylsvley Nature Reserve, was investigated as part of the Mogalakwena River Basin Study (Steffen Robertson \& Kirsten Inc., 1992). No calibration data were available, however, and the hydrological and hydraulic models used (WRSM90 and DAMBRK, respectively) were unable to simulate flows within the floodplain with sufficient certainty to describe the flooding process or to determine the volumes of water required to inundate the different vegetation zones. The study therefore recommended that further investigations would be necessary to enable the impact of the Olifantspruit Dam to be assessed adequately. In the interim, the possibility of supplying water to Nylstroom from the Roodeplaat Dam near Pretoria was mooted in 1993 and subsequently implemented. The Olifantspruit Dam remains an option for future development, however, and the need for modelling capability to assess its impact on the floodplain is likely to arise again.

Further attempts to model the flooding characteristics were carried out by Morgan (1996), using digital terrain modelling (DTM) and geographical information systems (GIS), but these could not provide the detail necessary for reliable impact assessment. In 1996 DWAF commissioned the study described here to develop the ability to model the hydrology and hydraulics of the Nyl River floodplain for the purpose of predicting impacts on the floodplain associated with development actions in the contributing catchments.

Predicting floodplain impacts requires linking development actions in the catchments to biotic responses in the floodplain. This is done in two stages. First, the effect of development on the volume and timing of water supply to the floodplain is predicted through hydrological modelling. The modelled water supply regime is then transformed through hydraulic modelling into the hydraulic conditions on the floodplain known to influence biota. In this study, floodplain vegetation habitat is used as an indicator of ecological impact, because some knowledge of the response of the vegetation to the occurrence of water is already available; responses of other organisms, e.g. fish could be considered in a similar way.

The study is presented in a paper in 3 parts. This paper (Part 1) presents the hydrological investigation and the setting up of hydrological models for the contributing catchments; further details of this investigation are presented by Pitman and Bailey (2003). The development of the hydraulic models is presented in Part 2 by Birkhead et al. (2007) while Part 3 (Kleynhans et al., 2007) presents scenario application of the models to demonstrate their performance and interpret the results.

\section{Hydrological modelling}

\section{Model requirements}

The area of floodplain modelled hydraulically is the most ecologically important part (in the opinion of the authors), extending from just downstream of the confluence of the Nyl River and the Olifantspruit to below the confluence of Bad se Loop and the Nyl River. (Fig. 2) (Birkhead et al., 2004) Hydrological modelling is therefore required to produce hydrograph inputs at the entry points of the contributing streams along this reach, i.e. at the points numbered from 1 to 5 in Fig. 2.

The hydraulic models require discharge inputs on a daily basis; this also defines the resolution required for the hydrological modelling. The DAYFLOW daily rainfall-runoff model (developed by Pitman, 1976) was applied to generate the hydraulic model inputs. The monthly WRSM2000 model (developed by Pitman et al., 2000) was set up to provide a comparison of output statistics for enhanced model confirmation, making it available for broader scale planning of the Mogalakwena Basin. The two models were set up for the catchments commanded by 10 flow-gauging stations that were suitable for calibration. These included all the stations shown on Fig. 1, except for those within the floodplain (A6H001 and A6H002), and station A6H022 which is unreliable but commands only a very small catchment area. The catchments beyond the study area commanded by gauging stations $\mathrm{A} 6 \mathrm{H} 023$ and $\mathrm{A} 6 \mathrm{H} 024$ were also calibrated so that hydrological models would be available should it become necessary to extend the hydraulic modelling to the lower regions of the floodplain in the future. Because the gauging stations are located upstream of the required floodplain entry points it was necessary to augment the gauged flows to account for the ungauged areas. This was done by empirical equations based on estimates of unit runoff downstream of the gauges.

\section{Hydrological data}

Application of DAYFLOW and WRSM2000 requires input data describing rainfall, evaporation and water use within the catchments. Calibration requires this information over an extended historical period together with corresponding runoff data.

Monthly and daily rainfall records were obtained from the Weather Bureau for a total of 28 rainfall stations within the contributing catchment areas. Data from these indicated that there is little variation in mean annual precipitation (MAP) over the area.

The monthly records contained relatively few gaps and missing data could be patched by regression with data from a nearby station. The best correlating station was selected from a number of candidates as the one showing the best correlation coefficient in regression with the target station. The percentage of months patched was less than $10 \%$ for all stations. After patching, all records were tested for stationarity by plotting residual mass curves, which were derived by accumulating the difference between each annual rainfall and the MAP for the entire record. In addition to visual inspection, the records were subjected to statistical analysis to identify any statistically significant trends. No significant trends were found in any of the selected records, although some records were too short for meaningful statistical analysis.

The modelling requires a historical sequence of rainfall inputs for each catchment. Most of the gauged sub-catchments 


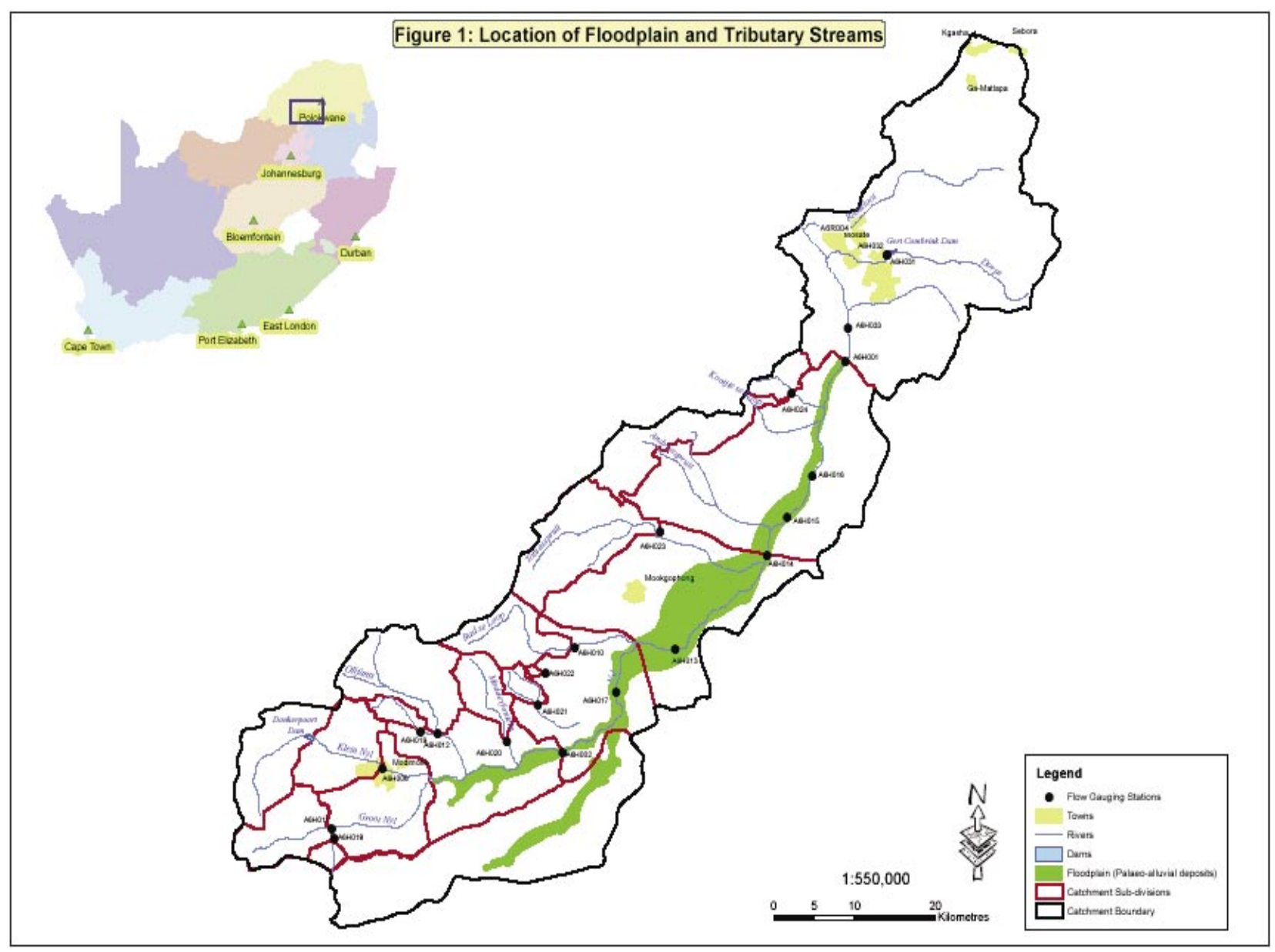

Figure 1

Location of floodplain and tributary streams

in the study area are small and the distribution of rainfall stations is relatively sparse - some sub-catchments do not contain even a single rainfall station. Five sub-catchment groupings were therefore created with areas large enough to contain an adequate number of rainfall stations. WRSM2000 includes a generation of catchment rainfall feature, which was used to generate monthly time series for each zone, expressed as percentages of MAP. Each time series spans the hydrological years 1920 through 2000, and all are reasonably consistent. Annual totals ranged from a low of $50 \%$ to $60 \%$ to a high of $130 \%$ to $150 \%$, with annual standard deviations in the range $19 \%$ to $22 \%$.

The daily rainfall records were less consistent compared to monthly records, mainly due to errors in assignment of individual storm values to the correct day when storms occurred over consecutive days. To overcome problems arising from such inconsistencies, a single representative station was selected for each of the five rainfall zones. These stations were selected on the basis of location and the length and completeness of the daily record. Four stations were selected (two of the rainfall zones being represented by the same station), of which three represent catchments in the study area, viz. station numbers 0589732A, 0590307 and 0590361 (Fig. 2).

Six evaporation stations are located within or close to the study area. These show that there is relatively little variation in mean annual evaporation (MAE) across the area, and a representative Symons pan value of $1700 \mathrm{~mm}$ has been used (Midgley et al., 1994).
Reliable modelling requires accurate assessment of water use within the catchments, which is mainly for irrigation. Past and present irrigation areas and usage were determined as part of the Mogalakwena Basin Study (MBS) (Steffen Robertson \& Kirsten Inc., 1992) and updated with more recent data obtained from Schoeman and Partners (Joubert, 2003). Cropping patterns, Apan evaporations, crop factors and effective rainfall factors were assumed to be similar for all sub-catchments. Irrigators in the Nylsvley area tend to rely on surface water (i.e. flowing streams and dams) when it is available, switching to boreholes when these resources are depleted. In order to simulate this practice the DAYFLOW model was amended as follows. The model was first run assuming all irrigation demand is supplied from surface water. All shortages are retained and the model was then re-run, supplying irrigation shortages from groundwater.

The registered and unregistered impoundment of water in dams can have a significant impact on downstream hydrology through interception of streamflow, evaporation, abstractions and releases (both controlled and uncontrolled). Modelling these effects requires specification of the dam characteristics. Storage capacities for registered dams were estimated from constructed capacity/surface area relationships. Unregistered dams were identified and their surface areas determined from aerial photographs, and their capacities assumed to be related to their surface areas by the same relationship as for the registered dams. Abstractions from Donkerpoort Dam to supply Modimolle constitute the only other significant impact on the hydrology of 


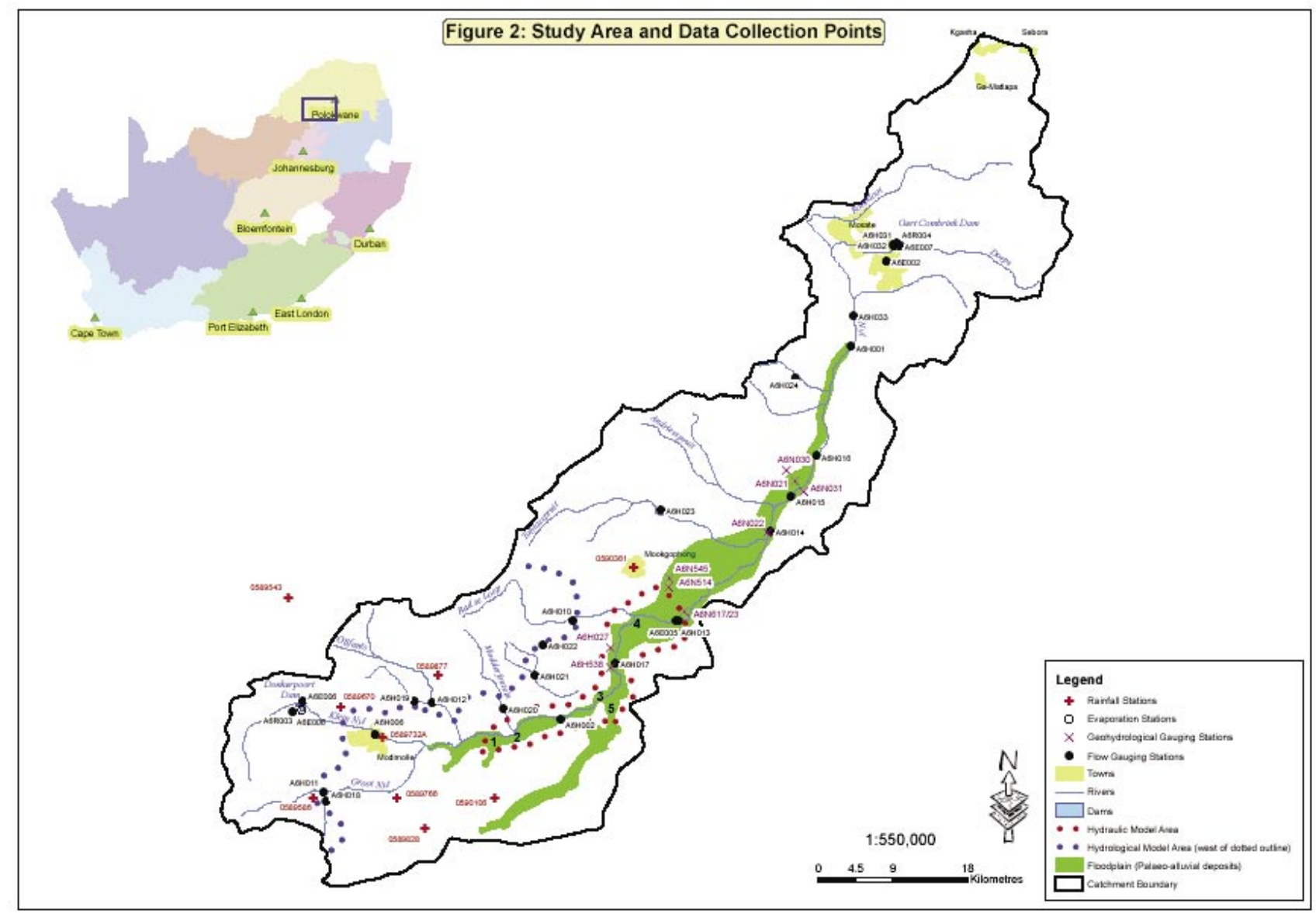

Figure 2

Study area and data collection points

gauged catchments in the study area, although these have virtually ceased since construction of the pipeline from Roodeplaat Dam in 1996.

Daily and monthly flow data were obtained from DWAF for 11 gauges for which discharge tables were available (Fig. 1). An evaluation of the records showed some deficiencies that required patching. As a first step, the monthly flow record for each gauge was patched by linear regression with the best correlating nearby gauge. For three of the records (A6H019, $\mathrm{A} 6 \mathrm{H} 022$ and $\mathrm{A} 6 \mathrm{H} 024)$ it was not possible to obtain correlation coefficients above 0.8 , and these were therefore patched with simulated flows after calibration of the monthly model (WRSM20000). To refine the patching of monthly flows, they were checked against monthly flows simulated by the daily model (DAYFLOW) after preliminary calibration, and the more realistic value (usually the simulated flow) selected. The final patching procedure was undertaken on the daily flow records, after an acceptable calibration had been obtained with the daily model.

For the hydraulic modelling, daily flows are required at the five entry points to the floodplain (Fig. 2) which are downstream from the flow gauging stations. For entry Point 5 there is no gauge, and the flow record was simulated using calibration parameters determined for the nearby gauged catchment A6H002 (this catchment makes a relatively small contribution to the floodplain in terms of MAR). For each of the other entry points the flow records were augmented to account for the intervening catchment area assuming that the unit runoffs upstream and downstream of a gauge are similar (equal to $0.012 \mathrm{~m}$ ) and proportioning by the DAYFLOW generated MAR values. For the areas below gauges $\mathrm{A} 6 \mathrm{H} 018, \mathrm{~A} 6 \mathrm{H} 011$ and $\mathrm{A} 6 \mathrm{H} 006$ to the confluence of the Groot and Klein Nyl Rivers, the unit runoff was determined from the combined gauge values and MARs scaled up by area.

\section{Calibration and verification}

The hydraulic model of the floodplain requires description of the hydrology of all the contributing streams. The available data enabled hydrological model calibration for ten gauged catchments within the study area (Fig. 2) (gauge A6H002 was considered to be unreliable for calibration purposes).

Model calibration was carried out on a station-by-station basis by selecting parameter values to ensure best agreement between observation and simulation. Observed monthly and annual flows were compared with those simulated by both the daily (DAYFLOW) and monthly (WRSM2000) models. Although daily flows are required as input to the hydraulic model, calibration of the monthly model was also carried out because the simpler monthly simulations are anticipated to be useful for broad water resource planning. Furthermore, the similar structure of the two models enables a good indication of appropriate model parameter values to be obtained from the monthly model. Plots of mean monthly flows and annual flows were compiled for all gauges for both the monthly and daily analyses in order to assess the goodness of fit between the observed and simulated values. The plots for gauge A6H012 are typical, and are presented in Figs. 3 and 4 for the monthly and daily analyses respectively. As expected, the higher resolution DAYFLOW model provides 


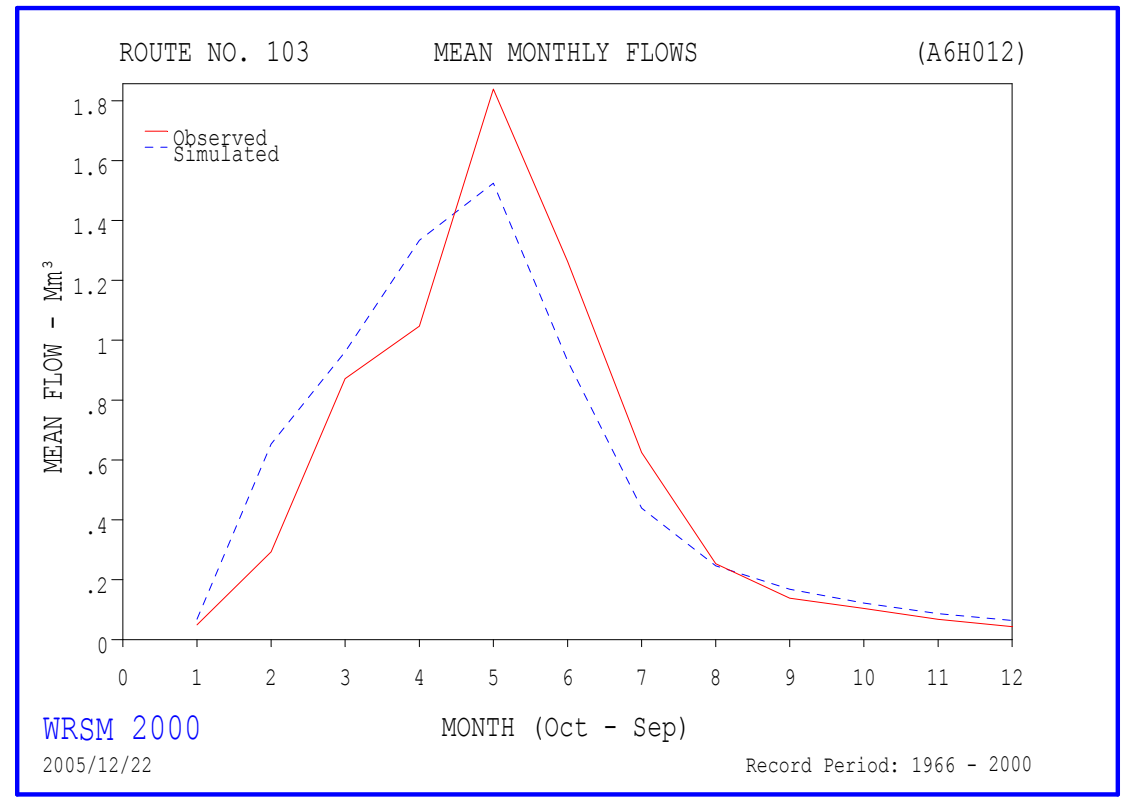

Calibrated monthly
and annual flows
for Gauge A6H012
by WRSM2000

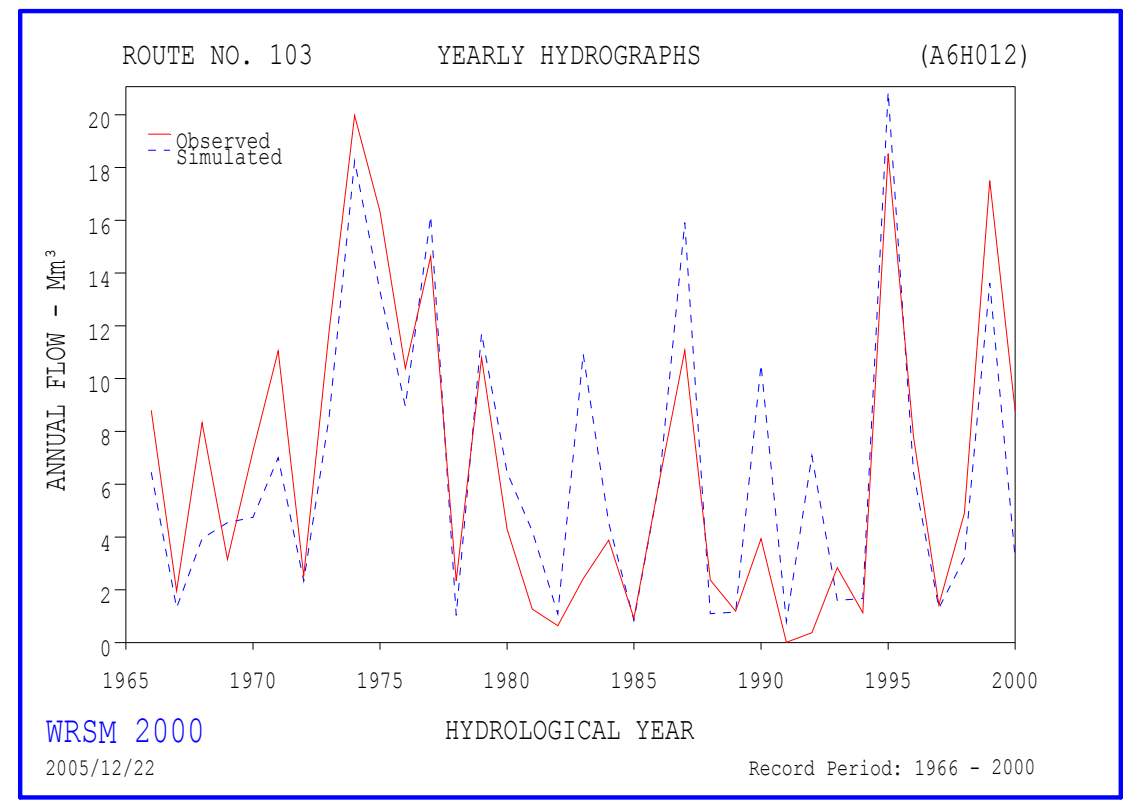

better predictions, and is used to simulate flows for input to the hydraulic model.

Because the Nyl River floodplain depends on periodic flooding for inundation, it is essential that the daily hydrological model simulate the flood regime of each tributary reliably. In order to verify the model's performance in this respect, the following two tests were undertaken:

- The predicted probabilities of observed and simulated flows exceeding a given threshold were compared

- The ranking of observed and simulated annual maximum daily flows were compared.

The stations selected for these additional tests were A6H006 (Klein Nyl River), A6H010 (Bad se Loop), A6H011 (Groot Nyl River) and A6H012 (Olifantspruit). These stations have relatively long records and are situated on the most important tributaries in terms of magnitude of flow and location (i.e. they enter the floodplain upstream or close to the most ecologically important sections of the floodplain). The threshold flow selected for the first test was $1.0 \mathrm{~m}^{3} / \mathrm{s}$. The probabilities were determined for daily flows exceeding this value and higher flows up to the maximum experienced. The probabilities of exceedance calculated from observed and simulated flows are virtually identical (Fig. 5, for gauging station A6H012). In the second test the maximum daily flows in each year were identified in the observed and simulated records. These maxima were then ranked and the ranking distributions compared graphically, the contention being that if the simulated and observed distributions match closely, the flood frequency characteristics will be adequately reproduced by the model. The comparison for gauging station A6H012 (Fig. 6) suggests reasonably realistic representation.

Additional confirmation of the performance of both the WRSM2000 and DAYFLOW models was obtained by comparison of simulated natural streamflow with results from other hydrological studies. In both the MBS and the Water Resources 1990 Study (Midgley et al., 1994) the Upper Nyl catchment was divided into two hydrological zones. The slopes of the Waterberg in the western part of the catchment 

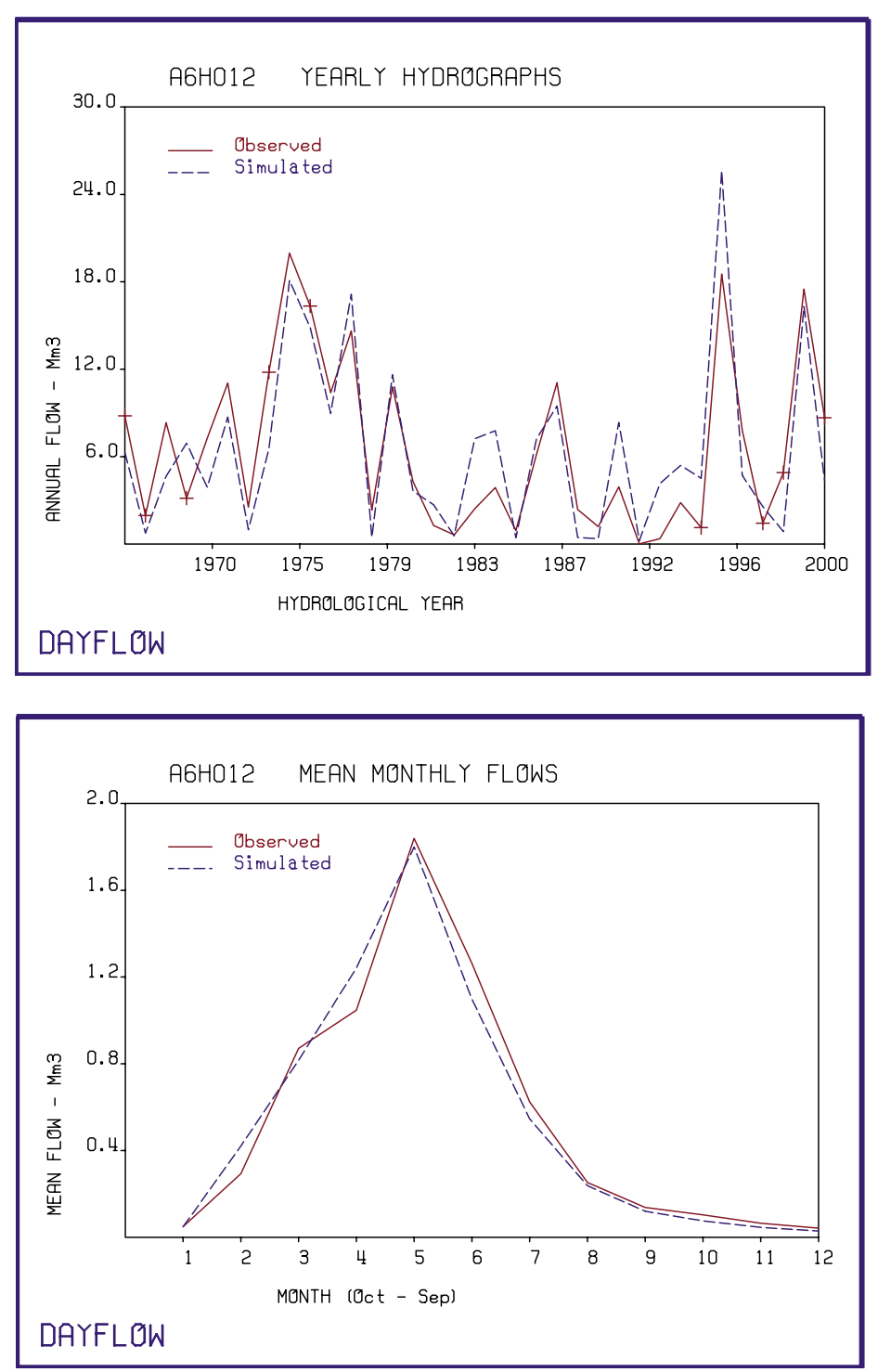

Figure 4

Calibrated monthly and annual flows for Gauge A6H012 by DAYFLOW constituted the zone of higher runoff, whereas the flat areas adjacent to the main stem of the Nyl formed the zone of relatively low runoff. This broad classification has been retained here. However, the variations in hydrological response of the steeper catchments (as determined in the calibration process) have been retained. Simulation of natural streamflows in the gauged catchments was undertaken using the calibrated parameter values. Parameters from the gauged catchments were generally adopted for the ungauged catchments, taking cognisance of catchment characteristics. The performance of both models was similar in the simulation of annual flows, but the daily model was superior in the generation of monthly flows. Values of mean annual runoff (MAR) simulated by the two models are compared in Table 1 with the MBS values for different locations. The results represent different periods, but the similarity of the WRSM2000 values for the periods 1950-2000 and 1920-2000 suggests that comparison with the MBS period (1910-1995) is not unreasonable. These results show that the MAR values predicted by the two models are similar, although the monthly model predicts slightly higher values for the ungauged flat areas. The monthly model predictions agree well with the MBS values, although the MBS values are generally higher in the upper tributaries and lower elsewhere. The greatest uncer- tainty in the simulations (including the MBS analysis) is related to the absence of well-defined channels and hence the lack of streamflow gauging in the flat portions of the study area adjacent to the floodplain. Nevertheless, the agreement between the various estimates of MAR (especially for the study area as a whole), together with the other confirmation tests described above, suggests adequacy of the models for the purposes of the study.

\section{Applications}

Development in the study area has been minimal but should there be further significant development (such as the construction of a storage dam on the Olifantspruit), the two models DAYFLOW and WRSM2000 could quantify the effect of this development on the flow regime. Output from the DAYFLOW model could be used as input to the hydraulic and ecological assessments (see Birkhead et al. (2007) and Kleynhans et al. (2007) respectively).

The WRSM2000 model is currently undergoing development with enhanced algorithms for wetlands, irrigation, groundwater, streamflow reductions, etc. While the overall results expressed in this paper would essentially remain the same, future analyses would benefit from the use of enhanced methodology. 


\begin{tabular}{|c|c|c|c|c|}
\hline \multicolumn{5}{|c|}{$\begin{array}{c}\text { TABLE } 1 \\
\text { Comparison of mean annual runoff (in } 10^{6} \mathrm{~m}^{3} / \mathrm{a} \text { ) obtained by different analyses }\end{array}$} \\
\hline Location & $\begin{array}{l}\text { DAYFLOW } \\
(1950-2000)\end{array}$ & $\begin{array}{l}\text { WRSM2000 } \\
(1950-2000)\end{array}$ & $\begin{array}{l}\text { WRSM2000 } \\
(1920-2000)\end{array}$ & $\begin{array}{c}\text { MBS } \\
(1910-1995)\end{array}$ \\
\hline Downstream of the Groot/Klein Nyl confluence & 20.1 & 18.8 & 19.6 & - \\
\hline Gauge A6H002 (Deelkraal) & 32.1 & 31.2 & 31.8 & 34.1 \\
\hline Downstream of the Bad se Loop/Nyl confluence & 42.9 & 41.7 & 42.5 & 44.9 \\
\hline Downstream of the Tobiasspruit/Nyl confluence & 49.8 & 49.1 & 51.2 & 51.1 \\
\hline Gauge A6H001 (Moorddrift) & 57.9 & 58.5 & 61.1 & 59.9 \\
\hline Upstream of the Rooisloot confluence & 65.7 & 70.5 & 75.8 & 72.6 \\
\hline
\end{tabular}

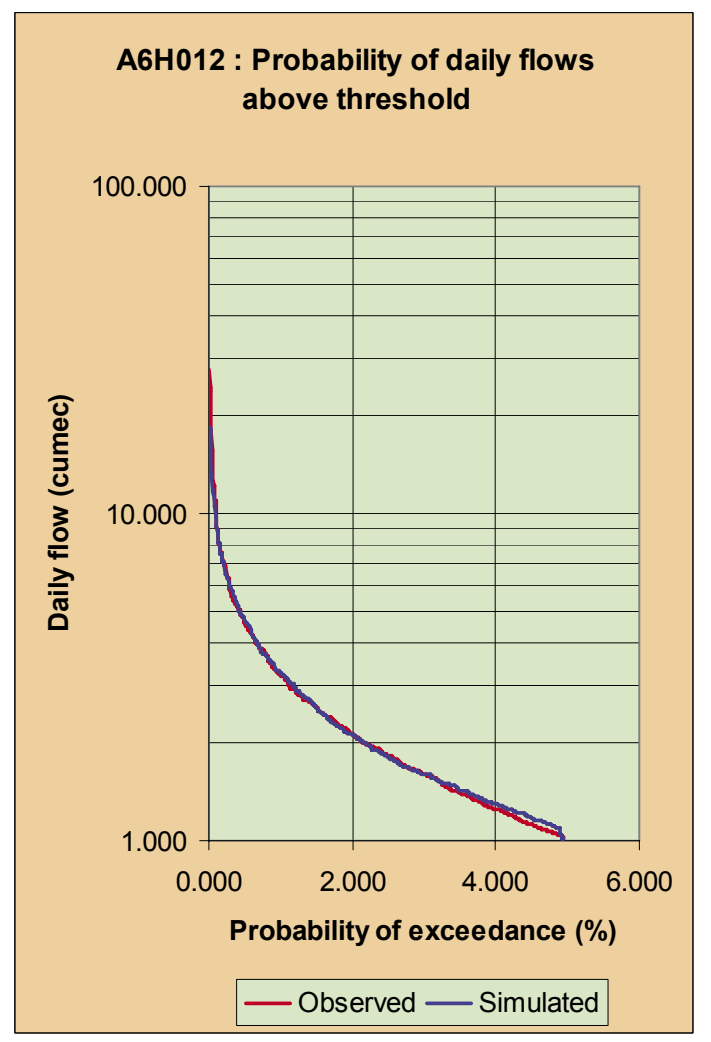

Figure 5

Probability of exceedance of flows greater than $1.0 \mathrm{~m}^{3} / \mathrm{s}$ determined from observed and DAYFLOW simulated data for gauging station A6H012

\section{Conclusions}

The catchments delivering water to the Nyl River floodplain were modelled using a daily flow model (DAYFLOW) (Pitman, 1976) and a monthly flow model (WRSM2000) (Pitman et al., 2000). The performance of the two models in producing mean monthly and mean annual flows was similar, with the daily model agreeing slightly better with observed flows than the monthly model. The monthly model is considered to be suitable for broad water resource planning, and the daily model for providing input to the hydraulic modelling of the floodplain.

The coverage of rainfall stations was generally poor, especially in the central and northern parts of the study area. Improvement of the fit between simulated and observed flows may occur if additional rainfall stations were installed rather than the use of any model with a higher degree of sophistication.

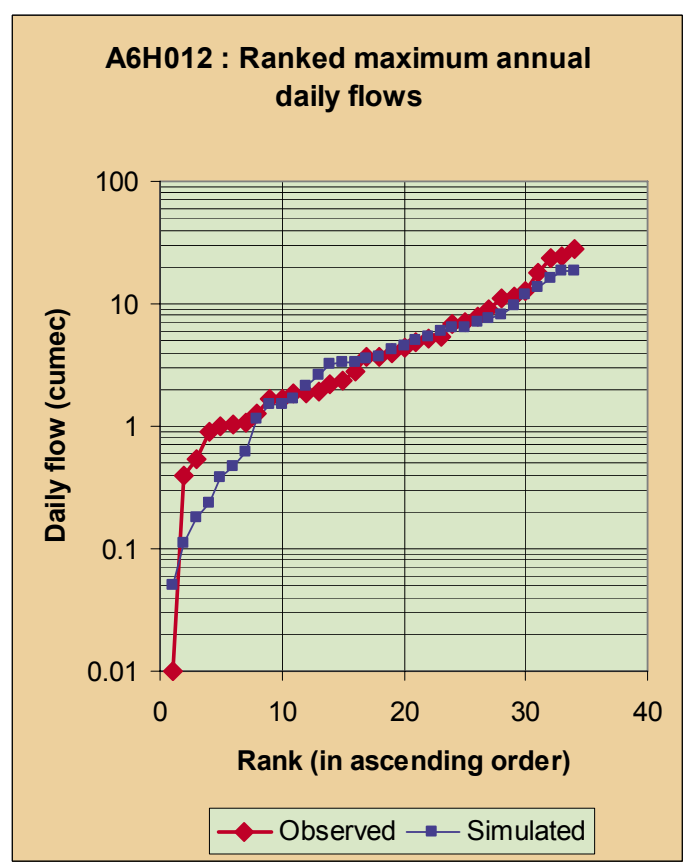

\section{Figure 6}

Ranked maximum annual daily flows determined from observed and DAYFLOW simulated data for gauging station A6H012

\section{Acknowledgements}

The authors would like to thank the Department's Director of Water Resources Planning, Mr JA van Rooyen, for initiating this study and for the opportunity to share this information in this publication.

\section{References}

BIRKHEAD AL, JAMES CS and KLEYNHANS M (2004) The Hydrologic and Hydraulic Study of the Behaviour of the Nyl River Floodplain: Hydraulic Modelling. Department of Water Affairs and Forestry Report No. P WMA 01/A61/00/0503, Pretoria, South Africa.

BIRKHEAD AL, JAMES CS and KLEYNHANS M (2007) Hydrological and hydraulic modelling of the Nyl River Floodplain. Part 2: Modelling hydraulic behaviour. Water SA 33 (1) 9-20.

JOUBERT (2003) Personal communication. Schoeman and Partners.

KLEYNHANS MT, JAMES CS and BIRKHEAD AL (2007) Hydrological and hydraulic modelling of the Nyl River Floodplain. Part 3: Applications to assess ecological impact. Water SA 33 (1) 21-26.

MIDGLEY DC, PITMAN and MIDDLETON BM (1994) Surface Water Resources of South Africa 1990. WRC Report No 298. Water Research Commission, Pretoria, South Africa. 
MORGAN CS (1996) The Application of Digital Terrain Models and a Geographical Information System in the Modelling of Flooding in the Nyl River Floodplain. Unpublished M.Sc. dissertation, University of the Witwatersrand, Johannesburg, South Africa.

PITMAN (1976) DAYFLOW daily rainfall-runoff model.

PITMAN WV, BAILEY AK and KAKEBEEKE JP (2000) The monthly WRSM2000 model.

PITMAN WV and BAILEY AK (2003) The Hydrologic and Hydraulic Study of the Behaviour of the Nyl River Floodplain: Hydrological Model Calibration. Department of Water Affairs and Forestry Report No. P WMA 01/A61/00/0403, Pretoria, South Africa.

ROGERS KH and HIGGINS SI (1993) The Nyl Floodplain as a Functional Unit of the Landscape, Preliminary Synthesis and Future Research. Report No. 1/93, Centre for Water in the Environment, University of the Witwatersrand, Johannesburg, South Africa.
STEFFEN ROBERTSON \& KIRSTEN INC. (1992) Water Resources Planning of the Mogalakwena River Basin: Situation Assessment and Development Potential. Report to Department of Water Affairs and Forestry, Pretoria, South Africa.

TARBOTON WR (1987) The Nyl Floodplain, Fauna and Flora. Vol. 45 (Special issue devoted Nylsvley). Transvaal Nature Conservation Division, Pretoria.

THERON, PRINSLOO, GRIMSEHL \& PULLEN INC (1991) Optimale Bevrediging van die Waterbehoeftes van Nylstroom. Unpublished Report, Nylstroom Town Council, Nylstroom, South Africa.

TOOTH S, McCARTHY TS, HANCOX PJ, BRANDT D, BUCKLEY K, NORTJIE E and MCQUADE S (2002) The geomorphology of the Nyl River and floodplain in the semi-arid Northern Province, South Africa. S. Afr. Geogr. J. 84 (2) 226-237. 